
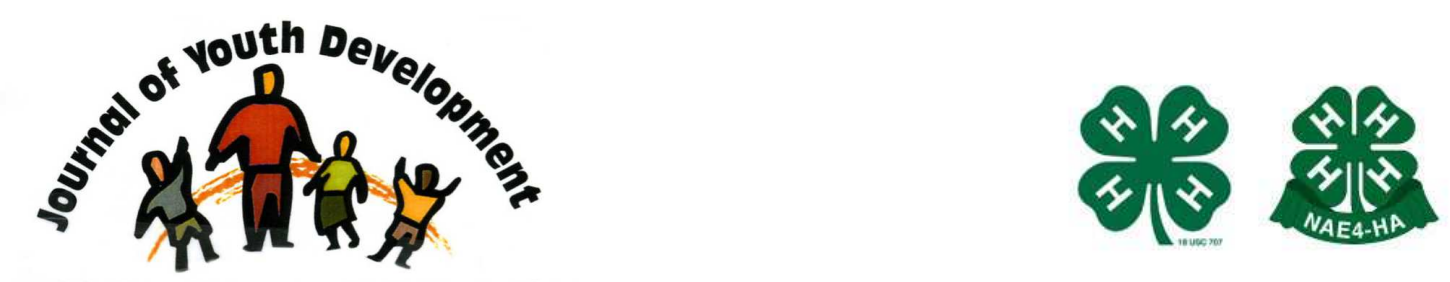

Bridging Research \& Practice

\title{
Working With Female Juvenile Delinquents: What Youth Practitioners Need to Know
}

\author{
Joy D. Patton \\ School of Social Work \\ University of Texas at Arlington \\ joy.patton@uta.edu
}




\section{JOURNAL OF YOUTH DEVELOPMENT \\ bridging research and practice

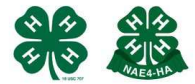

Volume 3, Number 2, Fall 2008

Article 080302FA006

\section{Working With Female Juvenile Delinquents: What Youth Practitioners Need to Know}

Joy D. Patton

University of Texas at Arlington

Abstract: This article is organized in a way to help youth practitioners recognize the most pertinent issues faced by female juveniles and to provide help in guiding professional interactions, communication and decision-making. The guidelines discussed are suggestions for practice based on an empirical review of the literature. Recent research has identified ten characteristics of female juvenile offenders to consider when working with this population. These areas include: (a) impaired cognitive functioning, (b) low academic achievement, (c) weak language skills, (d) peer relationships, (e) onset of menarche, $(f)$ early sexual experiences, $(g)$ mental illness, (h) victimization (i) low self-esteem and (j) race.

\section{Introduction}

A little more than a decade ago, the rate of female juvenile delinquency was not considered an issue of much concern. Most of the delinquent acts of females in previous decades primarily involved running away and sexual misconduct. However, Mullis, Cornille, Mullis, and Huber (2004) report an alarming trend for female juveniles between 1989 and 1993 that includes the following statistics: "court cases involving juvenile females with delinquency increased by $31 \%$ compared to a $21 \%$ increase for juvenile males [and] arrests for violent crimes increased $55 \%$ for juvenile females and by 33\% for juvenile males" (p. 206). The prevalence of female delinquents in the juvenile justice system has continued to increase dramatically. According to the U.S. Department of Justice (2003) there was a 59\% increase in the number of females involved with the juvenile justice system between 1990 and 1999.

In addition, the earlier a juvenile begins a life of offending, the longer the juvenile tends to offend turning into a chronic offender that extends into adulthood. According to Stone (2003), 
for minor delinquency, offending begins around age 7, peaks at ages 9 to 13, rises steadily to age 17 for boys and 15 for girls, and then drops. Nonviolent, serious delinquency also begins around age 7 and peaks at age 9 . For boys, it peaks again around age 12 and continues rising through age 19. For girls, it peaks again from ages 13 to 15, then declines. Violent offending for boys begins around age 7, then increases steadily from ages 8 to 19 . For girls, violent offending peaks around age 13, then declines.

At some point a youth practitioner will be called upon to work with the female juvenile delinquent. It is important to understand the characteristics of these juveniles and the issues that are most salient in working with them. Youth practitioners should be able to provide helpful strategies to these female juveniles as they work their way through these significant issues.

This article is organized in a way to help youth practitioners recognize the most pertinent issues faced by female juveniles and to provide help in guiding professional interactions, communication and decision-making. The guidelines that follow are suggestions for practice based on an empirical review of the literature.

Current research has identified ten characteristics of female juvenile offenders that were considered when developing practice guidelines for working with this population (Heckel et al., 1981; Lenssen et al., 2000; Leve, et al., 2004; Mullis et al., 2004; OJJDP, 1998; Weiler, 1999). The ten areas included:
(a) impaired cognitive functioning,
(b) low academic achievement,
(c) weak language skills,
(d) peer relationships,
(e) onset of menarche,
(f) early sexual experiences,
(g) mental illness,
(h) victimization,
(i) low self-esteem and
(j) race.

\section{Method}

The methodology for developing the practice guidelines for working with female juveniles began with performing a careful search of the literature. To ascertain the degree in which empirical studies have focused on female juvenile delinquent characteristics, an extensive search of electronic databases was performed. A basic search for female juvenile characteristics was performed in the literature on the Academic Search Premier, ERIC (EBSCO), Behavioral Science Collection and MedLine databases which resulted in several resources, three of which were selected for the purposes of this article (Lenssen et al., 2000; Mullis et al., 2004; OJJDP, 1998).

After identifying ten characteristics of female juvenile delinquents, a more advanced search was performed. Each search contained all ten female delinquent characteristics paired with female juvenile delinquent, female juvenile offender or female delinquent and practice, intervention or prevention methods. The advanced search extended to electronic databases including the Social 
Work Abstracts and Social Services Review and the Internet. This search yielded the following results that address the practice guidelines developed in this article.

\section{Practices Involving Female Juvenile Delinquent Characteristics}

Understanding the pattern of delinquency and where to begin working with female juvenile delinquents is a very complicated process. Some researchers have found that female delinquents have a lack of problem-solving skills and a tendency to avoid challenges, which can hinder healthy psychological and emotional functioning (Fejes-Mendoza and Miller, 1992). In addition, since there is an extremely high rate of physical and sexual abuse among female juvenile delinquents, this abuse contributes to a number of other delinquent acts as well as being intertwined with poor self-image, sexual attitudes, relationship with family, career and educational goals and further healthy development (Dembo, Williams, \& Schmeidler, 1993; Siegel \& Senna, 2000).

Even though working with female juvenile delinquent can be a complex process, research has identified characteristics common in female juvenile delinquents that can be helpful for youth practitioners in practice. The following are examples of how these common characteristics can be used as practice guidelines. However, the practice guidelines are meant to be just that, practice guidelines. It is still up to the practitioner to use discretion in choosing when and how to implement the suggested practices.

Impaired Cognitive Functioning. Scott (2003) suggests that impaired cognitive functioning is relative especially to a juvenile's ability to reason and understand. Decision-making capacities typically increase through childhood into adolescence but the decision-making abilities of juveniles is not equivalent to that of adults. Scott (2003) reports that "capacities to process information and to think hypothetically develop into adolescence, and cognitive performance improves generally due to knowledge gained in specific domains" (p. 302).

Youth practitioners can help juveniles develop decision-making skills in an effort to discourage participation in crime. Although research has not identified the best way in teaching decisionmaking skills to juveniles, Fischhoff, Crowell, and Kipke (1999) provide some tangible principles that include:

- teaching young people about how their emotions may influence their thinking and behavior

- encouraging young people to search for new information when making decisions and helping them to avoid overestimating their knowledge and capabilities

- providing accurate information to teens about the actual number of young people engaging in risky behaviors to counteract media messages

- utilizing concrete situations and decision problems that reflect young people's interests and have relevance to their lives

- using a general heuristic framework to help teenagers learn how to think critically about decision problems (e.g., "GOFER"-goals, options, facts, effects, and review; "going through the GOOP"-goals, options, outcomes, and probabilities)

- assisting young people to recognize their own biases

- providing adolescents with opportunities to practice and rehearse decision-making skills

- having teenagers work in pairs or small groups on relevant decision problems

- $\quad$ helping young people understand how their choices affect others. 
Low Academic Achievement. Female delinquents commonly have a record of poor academic performance. According to Booker-Loper (2000) "In one examination of incarcerated women, nearly half of the respondents had been expelled from school, and a disproportionate number had learning disabilities" (p. 13).

There is a high correlation among juvenile offenders with low academic achievement and offending as well as high recidivism rates. Youth practitioners can help female juveniles who are underachieving academically first by identifying the problem. It is very important to realize if underachievement is a result of a learning disability, frequent truancy, lack of opportunity or poor schooling.

According to Malmgren and Leone (2000), "a disproportionate number of incarcerated youth demonstrate poor reading skills...youth in correctional facilities read, on average, at the fourth grade level" (p. 239). Furthermore, "successful integration of delinquent youth into society requires that they posses reading skills that enable them to find and maintain competitive employment" (Malmgren \& Leone, 2000, p. 246). It is very important for youth practitioners to assess academic abilities to determine if remediation, tutoring or other educational programs would be beneficial in allowing the female juvenile to progress educationally.

Weak Language Skills. Research has found that language skill deficits are correlated with antisocial behavior. It is hypothesized that language deficits lead to antisocial behavior because language deficits result in poor behavioral self-regulation (Berk \& Potts, 1991; Burke, Crenshaw, Green, and Strocchia-Riveria, 1989). Gincola and Mezzich (2000) report that "Vygotsky and others asserted that this activity [children talking to themselves] is actually 'verbalized thought' that serves a self-regulatory function over behavior by guiding the child through his/her tasks. Accordingly, as language abilities mature and self-regulatory skills strengthen, audible verbalizations are no longer needed and are thus transformed into internalized verbal thought (i.e. internal speech) that exerts a regulatory role over behavior" (p. 360).

Because of findings between language skill deficits and antisocial behavior, youth practitioners will want to be mindful of cognitive interventions that strengthen the executive cognitive functioning in adolescents. These activities might include interventions that focus on social skills and on altering attitudes and behaviors that lead to violence through empathy, impulse control and anger management.

Peer Relationships. Current points of view realize peer groups influence juvenile behavior in connection with being a system of influence. Peer relations affect the parent-adolescent relationship. Dysfunction in the family generates opportunities for negative influence in deviant peer groups (Mullis et al., 2004). Relations with antisocial peers notably predict and preserve antisocial behaviors during adolescence (Walker-Barnes \& Mason, 2001). Likewise, adolescents who spend time with antisocial peers enhance their chances to be involved in crime, substance abuse and truancy (Engles \& Bogt, 2001).

There is much research to indicate that there are more favorable outcomes for female juveniles who have supportive parental and family systems. Youth workers can encourage, facilitate and work with juveniles and their families to promote a supportive family system. In addition, youth workers can encourage adolescent autonomy and individuation in peer group selection and participation as well as helping the juveniles realize how the peer group they associate with makes a difference in the decisions and outcomes in their lives. 
Onset of Menarche and Early Sexual Experiences. Early pubertal development has been linked to female juvenile delinquency. According to Haynie (2003) female delinquency and the female juvenile's pubertal development could be linked to delinquency in two ways: "First, the visible physical changes in appearance that result from puberty may signal to others that one is ready to take on more adult like roles... Second, girls experiencing puberty may find themselves in social context where there are greater opportunities to participate in delinquency..." (p. 356).

Youth practitioners should be cognizant of the female juvenile's relationship with her parents, encouraging cohesion and involvement (Bronte-Tinkew, Moore, \& Carrano, 2006). Research has found that continuous conflict in the parent-juvenile relationship and too much autonomy from the family in early adolescence propels juveniles toward delinquency (Haynie, 2003). Youth practitioners should also be concerned with the female juvenile's involvement in romantic behavior, which could lead to more exposure to deviant behavior. Lastly, youth practitioners should be aware that early pubertal development in female juveniles typically signals to others (parents and peers) that the juvenile is no longer a child and is ready for more adult-like behavior even though they may lack the necessary experience, reasoning and understanding to make those adult-like decisions.

Mental Illness. Much research has brought to light the high incidents of mental illness among youth, both males and females, in juvenile custody (Kataoka et al. 2001; Keplen, Abram, McClelland, Dulcan, \& Mericle, 2002; Ulzen \& Hamilton, 1998; Shelton, 2001). The research has found a high occurrence of psychological disorder in females in the juvenile justice system and these psychological disorders have a strong association with offender status (Dixon, Howie, \& Starling, 2004). Even though mental health status has surfaced as the leading factor linked with offending behavior, it remains a very low priority. In a recent study of 100 female juvenile offenders and 100 female juvenile non-offenders, Dixon, Howie, and Starling (2004) found that "rates of psychopathology were higher for offenders than for non-offenders with particularly high levels of conduct disorder ( $91 \%$ vs. $1 \%)$, substance abuse disorder ( $85 \%$ vs. $5 \%)$, depression (55\% vs. $25 \%$ ) and posttraumatic stress disorder (37\% vs. $4 \%$ )" (p. 1150$)$.

When working with a female juvenile offender, it is important for a youth practitioner to provide extensive screening and specific assessments to determine if and how much mental health is impaired. Youth practitioners should provide a comprehensive assessment and treat all symptoms of mental disorder present but should pay particularly close attention to juveniles with posttraumatic stress disorders (PTSD). An undiagnosed juvenile with PTSD may actually be mismatched with a treatment plan that could be rendered ineffective and could lead to reoffending (Mayfield-Arnold et al., 2003).

Victimization. Goodkind, $\mathrm{Ng}$ \& Sarri (2006) state that most of the involvement with the juvenile justice system by girls is typically due to assault and drug offenses. These authors suggest that the reason behind these offenses may very well be attributed to abuse suffered by the girls. These authors also state "experiences of abuse are particularly high among young women in the juvenile justice system, with estimates of up to $92 \%$ having experienced at least one form of emotional, physical, and/or sexual abuse, including 56\% reporting sexual abuse" (Goodkind et al., 2006).

In addition, Kazdin (2003) reports "delinquent youths have relatively high (32 percent) rates of PTSD [Post Traumatic Stress Disorder] [and] this results from the increased likelihood of exposure to physical abuse, sexual abuse, and domestic violence when compared to exposure 
to these experiences in non-delinquent samples. Exposure to trauma can lead to an increase in aggressive and antisocial behavior and ADHD" (p. 49). Mayfield-Arnold et al. (2003) also found that female juveniles who had been sexually abused had higher rates of depression, anxiety and suicidal thoughts.

Research on outcomes with sexually abused females suggests that cognitive-behavioral therapy has had the most potential in regards to types of treatment, especially when it focuses on specific abuse issues (Mayfield-Arnold et al., 2003). Youth practitioners should be mindful that many female juvenile delinquents are reluctant to disclose any sort of physical and/or sexual abuse and should offer repetitive inquiry throughout the treatment process in order to ensure self-disclosure when abuse has been present.

Low Self Esteem. Research over several decades has addressed the connection between low self-esteem and delinquency. For example, Kelley (1978) found a correlation between delinquency and low self-esteem. He found that as programs in schools were applied to increase the level of self-esteem, the frequency of delinquent behavior declined. Also, in a longitudinal study of 3,000 seventh graders Kaplan (1975) found that students with lower levels of self-esteem were more likely to assume deviant behavior patterns. Lastly, Davis (1991) identified ten factors that promoted violence, with the most common being poor self-image. It was found that juveniles participated in violence as a way to counterbalance their feelings of insecurity and low self-esteem.

According to Eccles and Gootman (2002) an important way in which to promote positive selfesteem is through providing opportunities to belong. More recently, it has been argued that juveniles do not receive the support they need from adults to facilitate a focus on their individual talents, which would provide confidence-giving success (Juvenile Justice FYI, 2006). Youth practitioners could help juveniles in finding mentoring programs that would foster the identification and development of talent as well as avenues for community involvement through volunteering or employment.

In addition, physical activity has been found to have positive effects in deterring delinquency and increasing self-esteem. According to a Brown University Child and Adolescent Behavior Newsletter (2006) "Physically active adolescents not only improve their health but also reduce their chances of getting into trouble. Teens who participate in a wide range of physical activities, particularly with their parents or at community recreation centers, are less likely to engage in sex, substance use, violence and delinquency than their sedentary peers who spend more time watching television or videos. Physically active teens were also less likely to have low self-esteem, and more likely to score better grades than their sedentary counterparts" (p. 2).

Race. What is known about juvenile delinquency in general, is that there is definitely a racial disparity in the juvenile justice system. Lum (2004) reports that "minority youth are more likely than their white counterparts to be arrested, held in jail, sent to juvenile or adult court for trial, convicted and given longer prison terms, leading to a situation in which the impact is magnified with each additional step into the juvenile justice system" (p. 224).

A nationally published report written by Eileen Poe-Yamagata and Michael A. Jones, senior researchers with the National Council on Crime and Delinquency and reported on by Lum (2004) found that African Americans under the age of 18 make up:

- 15 percent of their age group,

- 26 percent of those young people arrested, 
- 31 percent of those sent to juvenile court,

- 44 percent of those detained in juvenile jails,

- 32 percent of all juveniles tried in adult criminal courts,

- 40 percent of those sent to juvenile prisons, and

- 58 percent of all juveniles confined in adult prisons (p. 225).

In addition, Lum states, "black and Hispanic youths are treated more severely than white teenagers charged with comparable crimes at every step of the juvenile system..." (p. 224). He goes on to report that white adolescents charged with violent offenses have, on average a 193 day incarceration period after trial as compared to blacks who have an average incarceration period of 254 days after trial while Hispanic adolescents experience an average incarceration period of 305 days after trial.

Because the African American community highly values religion, involving the church could be a major strength for the adolescents of this community. Past research on the impact of religion on African American adolescent and psychosocial development indicates that religion acts as a buffer against the effects of neighborhood crime and serious involvement in crime (Johnson, Jeng, DeLi, \& Larson, 2000).

When working with African American families, youth workers need to be aware of the culture that surrounds this population as well as the most salient parenting practices that allow for welladjusted black adolescents. According to Lum (2004) African American families have a sense of shared responsibility for raising children. Not only does the parent influence the children's behavior but aunts, uncles, cousins and grandparents have very influential roles as well. However, "the most valued ties for many African Americans are the mother-child and sibling relationships" (Lum, 2004, p. 72).

Lum (2004) reports on six specific parenting practices that are linked to an African American child's success and include:

1. Child focused love or concern for their children and interest in their activities

2. Setting limits and discipline or clear expectations and rules in the home in terms of learning respect

3. High expectations or achievement at the highest level possible and advocacy when educational placement was below where the [it] is believed [they] should have been placed

4. Open, consistent, and strong communication or talking [in which] clear values and expectations as well as listening and advice [are] given

5. Positive racial and gender identification or transcending stereotypes and bias about being an African American and succeeding by using skills judiciously

6. Drawing upon community resources or supportive arenas such as the church, extended family, and occasionally the school; and use of relatives, neighbors, and high school teachers as role models, mentors and advocates at key junctures (p. 72).

\section{Conclusion}

It would be an understatement to assert that research on female juvenile delinquents and their needs have been essentially neglected in the research arena up until the recent past. There has no doubt been an outcry from youth practitioners for evidenced-based interventions to be 
developed for use in working with female juvenile delinquents. Although interventions and practices have not yet been established, researchers are beginning to understand and address this need.

This article was an attempt at pulling together the most pertinent information available for youth practitioners to have a guideline for practice with this population. Ten characteristics of female juvenile delinquents were identified and specific practice strategies for working with female juveniles who display these characteristics were discussed. While this article is intended to provide a road map of results found in the literature, it is still up to the practitioner to use discretion in choosing when and how to implement the suggested practices.

Lack of research and lack of gender-specific interventions in working with this population is a definite implication for further research. Research is beginning to address the concern for females in the juvenile justice system because many times females are treated in the same way as their male counterparts. Not only are these practices ineffective, they could prove more damaging to females in the long run when they are ushered through the system without effective interventions and this could quite possibly lead to chronic offending.

This paper also addresses the implication for policy change. The juvenile justice system does not see gender in regards to treatment of juveniles. The decisive juvenile justice issues that will persuade the formulation of youth policy into the 21st century entails the needs and strengths of youth and the role of legislators in taking on the problem of youth violence and victimization.

Policy changes that bring about understanding and action into these issues could help slow the rate of female juvenile offending. This could only be beneficial for individuals, neighborhoods, communities and states that suffer physical and financial losses due to female violent offenses.

When policy makers, researchers and youth practitioners join together to understand the needs of female juveniles and provide treatments that are effective, then the rate of female juvenile violent offenses will be reduced.

\section{References}

Berk, L., \& Potts, M. (1991). Development and functional significance of private speech among attention deficit hyperactivity disordered and normal boys. Journal of Abnormal Child Psychology, 19, 357-377.

Booker-Loper, A. (2000). Female juvenile delinquency: Risk factors and promising interventions. Retrieved July 16, 2006, from Juvenile Forensic Evaluation Resource Center Web Site: http://www.ilppp.virginia.edu/Juvenile Forensic Fact Sheets/FemJuv.html

Bronte-Tinkew, J., Moore, K.A., \& Carrano, J. (2006). The father-child relationship, parenting styles, and adolescent risk behaviors in intact families. Journal of Family Issues, 276), 850-881.

Brown University Child and Adolescent Behavior Newsletter. (2006). Physical activity and risky behavior in teens, 22(6), 2.

Burke, A., Crenshaw, D., Green, J. Schlosser, M., \& Strocchia-Riveria, L. (1989). Influence of verbal ability on the expression of aggression in physically abused children. Journal of American Academy of Child and Adolescent Psychiatry, 28, 215-218. 
Davis, E. (1991). Youth violence: An action research project. Journal of Multicultural Social Work, 1(3), 33-44.

Dembo, R., Williams, L., \& Schmeidler, J. (1993). Gender differences in mental health service needs among youths entering a juvenile detention center. Journal of Prison and Jail Health, 12, 73-101.

Dixon, A., Howie, P., \& Starling, J. (2004). Psychopathology in female juvenile offenders. Journal of Child Psychology and Psychiatry, 45(6), 1150-1158.

Eccles, J., \& Gootman, J.A. (2002). Community programs to promote youth development. National Research Council and Institute of Medicine.

Engels, R.C., \& Bogt, T.T. (2001). Influences of risk behaviors on the quality of peer relations in adolescence. Journal of Youth and Adolescence, 30, 675-696.

Fejes-Mendoza, K., \& Miller, D. (1992). Adolescent females with behavioral/emotional disorders: Old challenges, new approaches. Workshop conducted at the Severe Behavior Disorders Conference sponsored by Teachers Educators for Children with Behavioral Disorders, Washington, D.C.

Fischhoff, B., Crowell, N.A., \& Kipke, M. (1999). Adolescent Decision Making: Implications for prevention programs. Summary of a Workshop. Washington, DC: National Academy Press. (ERIC Document Reproduction Service No. ED441185).

Gincola, P.R., \& Mezzich, A.C. (2000). Executive cognitive functioning mediates the relationship between language competence and antisocial behavior in conduct-disordered females. Aggressive Behavior, 26, 359-375.

Goodkind, S., Ng, I., \& Sarri, R.C. (2006). The impact of sexual abuse in the lives of young women involved or at risk of involvement with the juvenile justice system. Violence Against Women, 12(5), 456-477.

Hayine, D.L. (2003). Contexts of risk? Explaining the link between girl's pubertal development and their delinquency involvement. Social Forces, 82(1), 355-397.

Johnson, B.R., Jeng, S.J., DeLi, S., \& Larson, D. (2000). Black youth crisis: The church as an agency of local social control. Journal of Youth and Adolescence, 25(4), 479-498.

Juvenile Justice FYI. (n.d.). Juvenile justice news. Retrieved July 17, 2006, from http://juvenilejusticefyi.com/juvenile justice news.html

Kaplan, H.B. (1975). Self attitudes and deviant behavior. Palasaides, CA: Goodyear.

Kataoka, S.H., Zima, B.T., Dupree, D.A., Moreno, K.A., Yang, X., \& MacCraken, J.T. (2001). Mental health problems and service use among female juvenile offenders: Their relationship to criminal history. Journal of the American Academy of Child and Adolescent Psychiatry, 40, 549555. 
Kazdin, A.E. (2003). Adolescent development, mental disorders, and decision-making of delinquent youths. In Grisso, T. \& Schwartz, R. G. (Eds.), Youth on trial: A developmental perspective on juvenile justice (pp. 33-65). Chicago: University of Chicago Press.

Kelley, T.M. (1978). Changes in self esteem among predelinquent youths in voluntary counseling relationships. Juvenile and Family Court Journal, 29, 74-87.

Keplen, L.A., Abram, K.M., McClelland, G.M., Dulcan, K.A., \& Mericle, A.A. (2002). Psychiatric disorders in youth in detention. Archives of General Psychiatry, 59, 1133-1143.

Lenssen, S.A.M., Doreleijers, T.A.H., van Dijk, M.E., \& Hartman, C.A. (2000). Girls in detention: what are their characteristics: A project to explore and document the character of this target group and the significant ways in which it differs from one consisting of boys. Journal of Adolescence, 23, 287-303.

Lum, D. (2004). Social work practice and people of color (5th ed.). Belmont, CA: Brooks/Cole Thomson Learning.

Malmgren, K.W., \& Leone, P.E. (2000). Effects of a short-term auxiliary reading program on the reading skills of incarcerated youth. Education and Treatment of Children, 23(3), 239-247.

Mayfield-Arnold, E., Kirk, R.S., Roberts , A.C., Griffith, D.P., Meadows, K., \& Julian, J. (2003). Treatment of incarcerated, sexually-abused adolescent females: An outcome study. Journal of Child Sexual Abuse, 12(1), 123-139.

Mullis, R.L., Cornille, T.A., Mullis, A.K., \& Huber, J. (2004). Female juvenile offending: A review of characteristics and contexts. Journal of Child and Family Studies, 13(2), 205-218.

Office of Juvenile Justice Delinquency and Prevention. (1998). What about girls? (Fact sheet \#84). Rockville, MD: OJJDP.

Scott, E.S. (2003). Criminal responsibility in adolescence: Lessons from developmental psychology. In Grisso, T. and Schwartz, R. G. (Eds.), Youth on trial: A developmental perspective on juvenile justice. (pp. 291-323). Chicago: University of Chicago Press.

Shelton, D. (2001). Emotional disorders in young offenders. Journal of Nursing Scholarship, 33, 259-263.

Siegel, L.J., \& Senna, J.J. (2000). Juvenile delinquency: Theory, practice, and law (7th ed.). Belmont, CA: Wadsworth Publishing.

Stone, S.S. (2003). Changing nature of juvenile offenders. Retrieved July 16, 2006, from Office of Juvenile Justice Delinquency and Prevention Web Site:

http://ojjdp.ncjrs.org/conference/track1.html

Ulzen, T P M., \& Hamilton, H. (1998). The nature and characteristics of psychiatric comorbidity in incarcerated adolescents. Canadian Journal of Psychiatry, 43, 57-63.

U.S. Department of Justice. (2003). Juvenile Court Statistics 1999. Washington, D.C: Office of Juvenile Justice and Delinquency Prevention. 
Walker-Barnes, C.J., \& Mason, C.A. (2001). Ethnic differences in the effect of parenting on gang involvement and gang delinquency: A longitudinal, hierarchical linear modeling perspective. Child Development, 72, 1814-1832.

Weller, J. (1999). An overview of research on girls and violence. Columbia University: Institute for Urban and Minority Education.

(C) Copyright of Journal of Youth Development Bridging Research and Practice. Content may not be copied or emailed to multiple sites or posted to a listserv without copyright holder's express written permission. Contact Editor at: patricia.dawson@oregonstate.edu for details. However, users may print, download or email articles for individual use. ISSN 2325-4009 (Print); ISSN 2325-4017 (Online) 